Disponível em:

http://editora.unoesc.edu.br/index.php/race

Race, Joaçaba, v. 15, n. 1, p. 95-114, jan./abr. 2016

\title{
O IMPACTO DA CRISE FINANCEIRA INTERNACIONAL SOBRE OS INVESTIMENTOS PÚBLICOS MUNICIPAIS
}

\section{The impact of international financial crisis on municipal public investments}

Flávio Ribeiro

E-mail: flavioribeiro@irati.unicentro.br Mestre em Contabilidade pela Universidade Federal do Paraná; Graduado em Ciências Contábeis pela Universidade Estadual do Centro-Oeste; Professor do Curso de Ciências Contábeis na Universidade Estadual do Centro-Oeste de Irati. Endereço para correspondência: PR 153, Km 7, Riozinho, 84500-000, Irati, Paraná, Brasil.

Willson Gerigk E-mail: gerigkw@gmail.com Mestre em Contabilidade pela Universidade Federal do Paraná; doutorando em Políticas Públicas na Universidade Federal do Paraná; Professor do Curso de Ciências Contábeis na Universidade Estadual do Centro-Oeste de Irati.

Artigo recebido em 14 de dezembro de 2014. Aceito em 30 de setembro de 2015. 
Resumo

Com o objetivo de identificar os efeitos da crise financeira de 2008 sobre o nível de investimentos municipais, na presente pesquisa se analisou a existência de diferença entre as médias dos investimentos públicos locais antes e após a crise internacional. A amostra compreendeu 3.449 municípios brasileiros distribuídos entre os 26 estados que compõem a Federação. Após a realização dos testes paramétricos, constatou-se que a amostra não apresentava característica normal. Diante disso, adotou-se o teste não paramétrico de Kruskal-Wallis para testar as seguintes hipóteses de pesquisa: $\mathrm{H}_{1}-$ A crise financeira de 2008 não afetou o nível de investimentos municipais e $\mathrm{H}_{2}$ - Os municípios de menor porte foram os mais afetados pela crise financeira de 2008. Os resultados estatísticos indicaram que a aplicação de recursos em investimentos públicos municipais foi impactada pela crise financeira de 2008, que seus reflexos mais evidentes ocorreram no ano 2009 e que, a partir de 2010, os níveis de investimentos públicos municipais voltaram aos patamares registrados antes da crise internacional, inclusive, aumentaram, refutando a hipótese 1 , de que os investimentos locais não teriam sofrido impactos da crise financeira de 2008. Constatou-se, também, que os municípios com população inferior a 50.000 habitantes foram os mais afetados, não se rejeitando a hipótese 2, sugerida na pesquisa. Palavras-chave: Crise financeira mundial. Investimentos municipais. Municípios brasileiros. Teste de médias.

\title{
The impact of international financial crisis on municipal public investments
}

\begin{abstract}
In order to identify the effects of the 2008 financial crisis on the level of municipal investments, this research analyzed the existence of differences between the means of local public investment before and after the international crisis. The sample included 3,449 municipalities distributed among the 26 states that make up the Federation. After performing parametric tests, it was found that the sample had no regular feature. Therefore, we adopted the nonparametric Kruskal-Wallis test to test the following research hypotheses: H1- The 2008 financial crisis did not affect the level of municipal investments and H2- The smaller municipalities were the most affected by the 2008 financial crisis. Statistical results indicated that the application of resources in public municipal investments was impacted by the 2008 financial crisis, that its most evident consequences occurred in 2009 and that, from 2010, the levels of municipal investments went back to the levels recorded before the international crisis, even increased, refuting the hypothesis 1 , that local investments would not have been impacted by the 2008 the financial crisis. It was also noted, that municipalities with less than 50,000 inhabitants were the most affected ones, not rejecting the hypothesis 2, suggested in the survey.

Keywords: Global financial crisis. Municipal investments. Brazilian municipalities. Mean test.
\end{abstract}




\section{INTRODUÇÃO}

A crise financeira e econômica de 2008 reacendeu os temores de uma nova depressão, na mesma dimensão vivida em 1929 (MATIAS-PEREIRA, 2010). A crise de 1929 atingiu vários países, especialmente os Estados Unidos da América, ocasionando o fechamento de diversos bancos e indústrias (RIBEIRO et al., 2011). Além desta, outras crises de menor alcance e relevância ocorreram de maneira localizada, como: em 1994 houve a crise mexicana; em 1999 a desvalorização do real no Brasil; em 2000 a bolha da Internet; e em 2001 a crise da Argentina.

Em meados de 2007, surgiram os primeiros indícios de uma nova crise financeira proveniente do mercado imobiliário norte-americano, que teve grande repercussão mundial nos anos subsequentes. Bresser-Pereira (2009) argumenta que a crise financeira de 2008 decorreu de uma cadeia de empréstimos originalmente imobiliários baseados em devedores insolventes. Assim, ao levar os gestores econômicos a preferirem a liquidez para cobrirem seus créditos, os inadimplentes levaram vários bancos e instituições financeiras à situação de falência.

A crise alcançou dimensões sísmicas em setembro de 2008 com o fracasso de Lehman Brothers e com o eminente colapso da gigante de seguros American Internacional Group (UNITED STATES OF AMERICA, 2011). O desdobrar da crise colocou a arquitetura financeira internacional em xeque, na medida em que trouxe à tona as limitações dos princípios básicos do sistema de regulamentação e supervisão bancária e financeira vigente.

Para Carcanholo (2008), o aumento da inadimplência, associado à queda dos preços dos imóveis, fez com que os agentes financeiros ficassem sem recursos para saldar seus compromissos, elevando a descapitalização dos grandes bancos em decorrência da forte redução na liquidez interbancária, propagando extremas incertezas econômicas. Diante desse contexto, não demorou muito para que a crise tomasse grandes proporções e influenciasse a economia mundial. Com a explosão da crise imobiliária, os mercados financeiros dos EUA e da Europa foram atingidos diretamente, pois suas instituições financeiras eram as principais negociantes das hipotecas de alto risco. No entanto, a crise rapidamente se espalhou, tornando-se mundial; com isso, um grande contingente de países passou a sentir as suas consequências, inclusive o Brasil.

Em face de um cenário ameaçador, os governantes da maioria dos países viram-se obrigados a tomar iniciativas emergenciais a fim de reduzirem os efeitos da crise, promovendo a isenção tributária e a oferta de crédito, com o objetivo de mitigar seus efeitos sobre suas economias (MATIAS-PEREIRA, 2010). 
No Brasil, segundo Gonçalves (2008), a eclosão da crise levou o Governo a tomar medidas orientadas especificamente para a expansão da liquidez. Houve maior disponibilidade de recursos para os agentes financeiros, flexibilização do redesconto, redução dos depósitos compulsórios para empresas exportadoras e construtoras e, também, expansão do crédito para o agronegócio.

Quanto ao setor público, diante da complexidade do Federalismo brasileiro, que congrega a União, os Estados e os Municípios, entendidos como Entes Públicos dotados de plena autonomia administrativa e financeira, as medidas adotadas, principalmente, pelo Governo Federal em relação à contenção e/ou aos estímulos visando à proteção e à manutenção da atividade econômica do País, precisam considerar os reflexos, em especial, sobre os entes municipais. Pelo fato de que, segundo Arretche e Vazquez (2005), as decisões de gastos dos municípios brasileiros são fortemente influenciadas pela legislação e pelo Governo Federal. Nesse contexto, na presente pesquisa tem-se como objetivo analisar o impacto da crise financeira de 2008 sobre os gastos realizados, pelos municípios brasileiros, em investimentos públicos no período de 2005 a 2011.

O estudo ajuda a preencher lacunas relacionadas ao entendimento do comportamento dos investimentos municipais, especificamente, quando se considera um período de turbulência econômica como o evidenciado pela Crise Financeira de 2008, visto que não foram encontrados estudos que tratassem do tema, o que apresenta uma possibilidade profícua de inserir essa temática na discussão teórica e, consequentemente, na verificação empírica no campo do ensino e pesquisa em contabilidade pública. O estudo é considerado descritivo e utiliza uma amostra de 3.449 municípios no período de 2005 a 2011, totalizando 24.143 observações.

Após essa introdução, discorre-se sobre a estrutura político-administrativa brasileira e os investimentos públicos; na sequência, apresenta-se a metodologia; depois, são evidenciados e discutidos os resultados empíricos da pesquisa, encerrando-se com as considerações finais.

\section{FUNDAMENTAÇÃO TEÓRICA E EMPÍRICA}


Na fundamentação teórica aborda-se a estrutura administrativa brasileira, tendo por base o Federalismo decorrente da Constituição Federal de 1988 e a conceituação sobre os gastos com investimentos públicos.

\subsection{ESTRUTURA POLÍTICO-ADMINISTRATIVA BRASILEIRA}

Diferentemente de muitas Federações, a brasileira, assim como a belga, é um sistema de três níveis (triplo federalismo) porque incorporou os municípios, e também os estados, como entes federativos, refletindo uma longa tradição de autonomia municipal e de escasso controle dos estados sobre as questões locais. A CF de 1988, no caso dos municípios, contrastou com as anteriores, em razão da provisão de mais recursos para as esferas subnacionais (SOUZA, 2005).

A descentralização promovida no Brasil pela CF de 1988, para Almeida e Carneiro (2003), seguiu uma tendência observada nas democracias ocidentais que objetivavam aproximar o governo dos cidadãos, por meio dos governos locais. Como o País passava por um período de transição do regime ditatorial para o democrático, essas tendências influenciaram as novas regras constitucionais e, também, foram vistas como uma resposta à centralização extrema de recursos e de decisão no Governo Central, existente no período militar. Ainda, segundo Souza (2002), existia a promessa de tornar os governos municipais mais eficientes e acessíveis às demandas dos cidadãos (SOUZA, 2002).

A Federação brasileira tem sido marcada por políticas públicas federais que se impõem às instâncias subnacionais. Poucas competências constitucionais exclusivas são alocadas aos estados e municípios, como também ocorre em outros países em desenvolvimento, como o México e a África do Sul. Por outro lado, estados e municípios possuem autonomia administrativa considerável, responsabilidades pela implementação de políticas aprovadas na esfera federal, inclusive muitas decorrentes de Emendas Constitucionais, e parcelas dos recursos públicos provenientes do Governo Federal, principalmente para os municípios, que são superiores ao evidenciado em outros países em desenvolvimento (SOUZA, 2005).

Para Arretche e Vazquez (2005), os municípios brasileiros têm suas decisões de gasto fortemente induzidas pela legislação federal, como exemplos têm-se a realizadas nas áreas de educação e saúde, em que existem percentuais mínimos a serem aplicados definidos constitucionalmente, 25\% e 15\% das receitas originárias de impostos, respectivamente. Além, de outras normas que regulam os montantes e o tipo de gastos locais, como o Fundo de Manutenção e Desenvolvimento da Educação Básica e de Valorização dos Profissionais da Educação (Fundeb), por exemplo. 
Com essa forte interferência sobre os governos municipais, a distribuição intergovernamental de competências no Brasil está longe de corresponder às características esperadas de um modelo idealizado de Federalismo, em que os governos locais têm autonomia para tomar decisões sobre uma ampla gama de áreas de atuação. Se as teorias normativas da descentralização supõem governos locais dotados de autonomia para atender às demandas de seus cidadãos, está claro que os municípios brasileiros não correspondem ao que se chama genericamente de “poder local”. As administrações municipais têm sua agenda de governo fortemente afetada por legislação federal. Mesmo para captar recursos, o caso brasileiro está muito distante do previsto pela teoria do federalismo fiscal, que supõe que as finanças locais sejam disciplinadas pelo mercado (ARRETCHE; VAZQUEZ, 2005).

A partir da CF de 1988, os municípios passaram a ter maior autonomia administrativa e financeira, mediante a descentralização de políticas públicas para o nível municipal e a reorganização do sistema de tributação e redistribuição de receitas da União e dos estados aos municípios. Entretanto, o que se observou foi o aumento das atribuições dos entes municipais perante a população sem a devida contrapartida financeira; as contingências decorrentes do porte dos municípios e a sua localização geográfica influenciam sua capacidade financeira de autofinanciamento via sistema tributário (SOUZA, 2004; SOUZA, 2005; ARRETCHE; VAZQUEZ, 2005).

O sistema de autofinanciamento vigente privilegia o governo federal em detrimento dos demais entes públicos que integram a Federação. Essa concentração de receitas tributárias e a forma de sua redistribuição pela União influenciam fortemente as administrações municipais e condicionam, em grande extensão, as ações dos governos locais, conforme dados da Tabela 1.

Tabela 1 - Demonstrativo do percentual das receitas tributárias, das receitas de participação nas receitas da União e dos Estados, na formação das receitas correntes municipais nos anos 2000 e 2011 


\begin{tabular}{|c|c|c|c|c|c|c|}
\hline & \multicolumn{3}{|l|}{2000} & \multicolumn{3}{|l|}{2011} \\
\hline $\begin{array}{l}\text { Faixa popula- } \\
\text { cional }\end{array}$ & \multicolumn{3}{|c|}{$\begin{array}{l}\text { \% de participação na Receita Cor- } \\
\text { rente }\end{array}$} & \multicolumn{3}{|c|}{$\begin{array}{l}\text { \% de participação na Receita Cor- } \\
\text { rente }\end{array}$} \\
\hline Municípios & Receita & $\begin{array}{r}\text { Participa- } \\
\text { ção }\end{array}$ & $\begin{array}{r}\text { Participa- } \\
\text { ção }\end{array}$ & Receita & $\begin{array}{r}\text { Participa- } \\
\text { ção }\end{array}$ & Participação \\
\hline Brasileiros & $\begin{array}{r}\text { Tributá- } \\
\text { ria } \\
\end{array}$ & $\begin{array}{r}\text { Receitas da } \\
\text { União } \\
\end{array}$ & $\begin{array}{r}\text { Receitas do } \\
\text { Estado } \\
\end{array}$ & $\begin{array}{r}\text { Tributá- } \\
\text { ria } \\
\end{array}$ & $\begin{array}{r}\text { Receitas da } \\
\text { União } \\
\end{array}$ & $\begin{array}{r}\text { Receitas do } \\
\text { Estado } \\
\end{array}$ \\
\hline Até 5 mil & 3,11 & 53,59 & 22,16 & 3,98 & 50,17 & 21,11 \\
\hline De 5 a 20 mil & 5,61 & 38,89 & 24,75 & 5,91 & 34,94 & 21,10 \\
\hline De 20 a 50 mil & 10,64 & 26,08 & 26,85 & 9,35 & 26,34 & 21,42 \\
\hline De 50 a 100 mil & 14,50 & 20,16 & 30,05 & 12,76 & 19,32 & 23,34 \\
\hline De 100 a $500 \mathrm{mil}$ & 21,37 & 12,84 & 30,43 & 19,41 & 11,69 & 25,81 \\
\hline $\begin{array}{l}\text { De } 500 \text { mil a } 1 \\
\text { milhão }\end{array}$ & 22,88 & 8,13 & 32,64 & 23,47 & 7,96 & 27,53 \\
\hline $\begin{array}{l}\text { Acima de } 1 \\
\text { milhão }\end{array}$ & 38,17 & 4,32 & 25,79 & 38,26 & 4,65 & 22,20 \\
\hline
\end{tabular}

Fonte: Tesouro Nacional (2000, 2011).

Nota: Percentuais calculados a partir dos valores médios e utilizando os municípios que disponibilizaram seus dados na STN.

A Tabela 1 mostra que a situação financeira dos municípios brasileiros, de 2000 para 2011, não apresenta grandes modificações. A característica básica evidenciada é que, quanto menor o porte dos municípios, maior é a sua dependência financeira em relação às transferências constitucionais da União e dos Estados e menor é sua capacidade de autofinanciar-se por meio da tributação municipal. No caso dos municípios extremamente pequenos, com menos de cinco mil habitantes, a participação nas receitas da União e dos Estados, tanto em 2000 quanto em 2011, representou mais de 70\% das receitas correntes municipais. Considerando, ainda, que esses municípios contam com as transferências multigovernamentais do Fundeb, a dependência financeira é ainda maior.

Essa situação de dependência financeira e de baixa capacidade de tributação própria é invertida apenas nos municípios que possuem população acima de um milhão de habitantes. Nestes, a capacidade de arrecadação é centrada nos impostos municipais e são estes que contribuem de forma efetiva para sustentar as despesas municipais e as políticas públicas. Ou seja, à medida que o município apresenta maior desenvolvimento econômico e melhores possibilidades para o crescimento individual dos munícipes, maior a concentração de população e, consequentemente, melhor a sua capacidade de arrecadação própria. 
Logicamente, esses fatores trazem maior complexidade na prestação dos serviços públicos municipais. As características financeiras dos municípios brasileiros, certamente, influenciam as decisões sobre a aplicação de recursos em novos investimentos públicos. Visto que a maioria depende, em grande medida, das transferências da União e dos Estados, estes, por sua vez, precisam que a economia esteja em desenvolvimento para manterem seus níveis de arrecadação, as engrenagens do complexo federalismo brasileiro e, consequentemente, os níveis de investimentos dos entes subnacionais, em especial, nos municípios.

\subsection{INVESTIMENTOS PÚBLICOS}

A economia brasileira, apesar da estabilidade econômica, vem enfrentando ao longo do tempo o desafio atender à necessidade de investimentos públicos. As carências de infraestrutura acentuam as desigualdades sociais e regionais na economia brasileira. A característica concentradora do crescimento brasileiro proporcionou, historicamente, a formação de uma sociedade com um dos maiores índices mundiais de desigualdade (DOMINGUES; VIANA; OLIVEIRA, 2007).

Borges (2010) exemplifica a clássica distinção entre bens públicos e privados: enquanto bens privados puros são rivais e excludentes, bens públicos são não rivais e não excludentes. Por exemplo, políticas de controle da poluição produzem um bem público, que é uma atmosfera mais limpa. Em princípio, ninguém pode ser excluído do consumo desse bem (não exclusão). Além disso, o fato de um indivíduo “A” usufruir de uma atmosfera mais limpa não reduz (em tese) a quantidade desse benefício disponível para os demais (não rivalidade). No caso dos bens privados, isso não se verifica, pois se o indivíduo "A” comprar a última maçã disponível no supermercado, os demais consumidores não mais poderão usufruir desse bem.

É preciso notar que bens públicos e bens privados representam situações extremas, tipos-ideais que raramente correspondem ao mundo empírico. As políticas em áreas como saúde, educação, saneamento, etc. envolvem a oferta dos chamados bens públicos locais. Trata-se de bens não divisíveis que geram externalidades positivas de âmbito local (ex.: uma ponte, uma escola) (BORGES, 2010). Os investimentos públicos são caracterizados como despesas de capital que originam novos bens (adquiridos ou formados). Para Nascimento (2006, p. 155), os investimentos públicos envolvem “[...] o planejamento e a execução de obras, inclusive com a aquisição de imóveis considerados necessários à realização dessas obras, e com a aquisição de instalações, equipamentos e material permanente.” 
Os investimentos públicos são aplicações de recursos que resultam na obtenção de novos bens de capital por parte das entidades públicas e decorrem da realização de obras e/ou da aquisição de materiais ou equipamentos permanentes novos. Os investimentos públicos visam à expansão e/ou melhorias da forma de realizar a prestação dos serviços públicos à população, como, por exemplo, pela construção de escolas, creches, postos de saúde, ou pela aquisição de equipamentos: médicos, odontológicos, máquinas, veículos, etc., ou, ainda, pela restauração de bens já existentes, colocando-os em condições de novamente prestarem serviços à sociedade (SLOMSKI, 2006; ANDRADE, 2007; KOHAMA, 2010).

O investimento público, historicamente, constitui-se em uma das alavancas do crescimento econômico brasileiro (DALL'ACQUA, 2005). São exemplos de investimentos realizados pelos municípios, nesse sentido, as obras de infraestrutura, como a construção de uma estrada ou uma pavimentação asfáltica; esse investimento valorizará os imóveis localizados naquela área, proporcionará melhoria nas condições de tráfego na região, gerará, temporariamente, empregos durante a execução da obra e, ainda, de forma futura, poderá contribuir para investimentos privados na região, gerando externalidades presentes e futuras. Outro exemplo de investimento público é a aquisição de ônibus destinados ao transporte escolar, que beneficiam diversos alunos, por meio do acesso à educação, além de proporcionarem mais segurança no transporte dos educandos.

\section{ASPECTOS METODOLÓGICOS}

Esta pesquisa foi delineada a partir do teste de Kruskal-Wallis, para dados não paramétricos. A abordagem do estudo é teórico-empírica; quanto ao problema e ao objetivo de pesquisa, caracteriza-se por ser descritiva e quantitativa, respectivamente.

\subsection{CARACTERIZAÇÃO DA AMOSTRA}

A amostra da pesquisa foi constituída a partir do banco de dados Finanças do Brasil (Finbra), da Secretaria do Tesouro Nacional (STN); os dados se referem aos gastos com investimentos públicos realizados pelos municípios brasileiros no período de janeiro de 2005 a dezembro de 2011. A escolha do período deve-se ao fato de que intervalos menores poderiam ser incapazes de detectar confiavelmente a diferença entre a média dos investimentos municipais, influenciando os resultados da pesquisa. A seleção da amostra foi realizada de forma não probabilística e por conveniência, conforme Tabela 2 . 
Flávio Ribeiro, Willson Gerigk

Tabela 2 - Seleção da amostra

\begin{tabular}{lrr}
\hline Critérios & Número de empresas & $\%$ \\
\hline Municípios brasileiros & 5.570 & 100 \\
Municípios com ausência de informações & $(2.119)$ & $(38,08)$ \\
\hline Amostra final & 3.449 & 61,92
\end{tabular}

Fonte: elaborada pelos autores com dados da Finbra/STN (2005-2011).

Conforme os critérios da Tabela 2, a amostra final é representada por 3.449 municípios, totalizando 24.143 observações, no período analisado. O parâmetro tomado para a exclusão dos municípios da amostra foi a falta de divulgação de dados sobre os gastos com investimentos em algum dos anos pesquisados. A classificação discriminada por Estados é observada na Tabela 3.

Tabela 3 - Amostra final por Estados

\begin{tabular}{|c|c|c|}
\hline Estados & Municípios & $\%$ \\
\hline Acre & 8 & 0,23 \\
\hline Alagoas & 61 & 1,77 \\
\hline Amazonas & 25 & 0,72 \\
\hline Amapá & 6 & 0,17 \\
\hline Bahia & 172 & 4,99 \\
\hline Ceará & 125 & 3,62 \\
\hline Espírito Santo & 51 & 1,48 \\
\hline Goiás & 135 & 3,91 \\
\hline Maranhão & 84 & 2,44 \\
\hline Minas Gerais & 531 & 15,40 \\
\hline Mato Grosso & 57 & 1,65 \\
\hline Mato Grosso do Sul & 75 & 2,17 \\
\hline Pará & 35 & 1,01 \\
\hline Paraíba & 125 & 3,62 \\
\hline Pernambuco & 131 & 3,80 \\
\hline Piauí & 117 & 3,39 \\
\hline Paraná & 285 & 8,26 \\
\hline Rio de Janeiro & 49 & 1,42 \\
\hline Rio Grande do Norte & 87 & 2,52 \\
\hline Rio Grande do Sul & 427 & 12,38 \\
\hline Roraima & 5 & 0,14 \\
\hline Rondônia & 35 & 1,01 \\
\hline Santa Catarina & 245 & 7,10 \\
\hline Sergipe & 42 & 1,22 \\
\hline São Paulo & 471 & 13,66 \\
\hline Tocantins & 65 & 1,88 \\
\hline Total & 3.449 & 100 \\
\hline
\end{tabular}

Fonte: os autores. 
A distribuição dos municípios por Estados (Tabela 3) evidencia que Minas Gerais, São Paulo e Rio Grande do Sul são mais representativos, com 15,40\%, $13,66 \%$ e 12,38\% da amostra, respectivamente. O Estado de Roraima apresentou menor número de municípios, apenas cinco, o que representa $0,14 \%$ do total da amostra.

\subsection{HIPÓTESES E VARIÁVEIS DA PESQUISA}

A pesquisa tem como objeto de análise os gastos realizados pelos municípios brasileiros em investimentos públicos. O objetivo é verificar se, no período da crise financeira internacional de 2008, ocorreram modificações estatisticamente significantes sobre os volumes de gastos nessa natureza da despesa pública local, ou seja, se o evento da crise de 2008 impactou a forma como os gestores municipais vinham aplicando seus recursos públicos. Assumindo, para tanto, conforme defendido por Mathias-Pereira (2010), que os gastos com investimentos públicos são sensíveis às modificações abruptas no ambiente mundial e que essas modificações podem afetar diretamente o nível de gastos municipais com investimentos públicos. Com base nisso, a hipótese da presente pesquisa é a seguinte:

$\mathrm{H}_{1}-$ A crise financeira de 2008 afetou o nível de investimentos municipais.

De acordo com Souza (2004), as transferências federais representam a principal fonte de recursos para os municípios de pequeno e médio porte, ou seja, municípios mais pobres e com menor população. Assim, adotando como pressuposto a dependência dos menores municípios aos recursos federais, pretende-se testar a seguinte hipótese:

$\mathrm{H}_{2}-$ Os municípios de menor porte foram os mais afetados pela crise financeira de 2008.

Para captar como os gastos municipais em investimentos estavam sendo realizados pelos municípios e como passaram a ser após a crise de 2008, o período de coleta de dados foi dividido em dois intervalos: (i) antes da crise e (ii) após a crise. O primeiro intervalo se estendeu de 01 de janeiro de 2005 a 31 de dezembro de 2007, e o segundo, de 01 de janeiro de 2009 a 31 de dezembro de 2011, perfazendo 20.694 observações. Adotou-se tal procedimento como forma de neutralizar o ano 2008, no qual a crise financeira ocorreu. 


\subsection{TRATAMENTO DOS DADOS}

A comparação de parâmetros populacionais, como média, variância, mediana, etc., pauta-se em testes paramétricos (que exigem distribuição amostral conhecida ou normal) e em testes não paramétricos (que não necessitam o conhecimento da distribuição amostral). Os testes não paramétricos se configuram como alternativa aos testes paramétricos (MAROCO, 2003).

Para a aplicação de testes paramétricos é necessária a verificação simultânea de que (i) a variável dependente possua distribuição normal e (ii) as variâncias populacionais sejam homogêneas caso as análises objetivem comparar duas ou mais amostras (MAROCO, 2003).

Inicialmente, foram realizados testes de normalidade das amostras, cujo resultado é discriminado na Tabela 4.

Tabela 4 - Teste de normalidade das amostras

\begin{tabular}{|c|c|c|c|c|}
\hline \multicolumn{5}{|c|}{ Teste de Normalidade } \\
\hline \multirow{4}{*}{ Investimentos } & \multirow{2}{*}{ Crise } & Kolmogor & & \\
\hline & & Estatística & df & Significância \\
\hline & Antes & 0,449 & 10347 & 0,000 \\
\hline & Após & 0,444 & 10347 & 0,000 \\
\hline
\end{tabular}

Fonte: os autores.

O teste de Kolmogorov-Smirnov (K-S) é usado para indicar se a distribuição da variável de estudo provém de uma população com distribuição normal. Os resultados do teste $K-S$ para duas amostras “antes da crise” e "depois da crise” com $p$-value (Significância) de 0,000 e 0,000, respectivamente, rejeitam, com uma probabilidade de erro de 5\%, a hipótese de distribuição normal das amostras.

A segunda condição a ser verificada é a homogeneidade da amostra. Na Tabela 5 apresentam-se os resultados do teste Levene empregado nessa finalidade.

Tabela 5 - Teste de homogeneidade da amostra

\begin{tabular}{llllll}
\hline Teste de Homogeneidade & & & & \\
\hline & & Estatística de & df1 & df2 & p-value (Sig.) \\
& $\begin{array}{l}\text { Levene } \\
\text { Based on Mean }\end{array}$ & 31,817 & 1 & 20692 & 0,000 \\
& Based on Median & 16,232 & 1 & 20692 & 0,000 \\
Investimentos & Based on Median and with & 16,232 & 1 & 17845,864 & 0,000 \\
& adjusted df & 17,110 & 1 & 20692 & 0,000 \\
\hline
\end{tabular}

Fonte: os autores. 
Para verificar a homogeneidade, a significância ( $p$-value) deve ser maior que 5\% (Sig. > 0,05). Diante do resultado do teste de Levene, pode-se concluir que as variâncias populacionais estimadas não são homogêneas, pois o nível de significância ( $p$-value) do teste $(0,000)$ não foi capaz de rejeitar a $\mathrm{H}_{0}$ : que as variâncias das duas amostras não são homogêneas, indicando que as variáveis analisadas possuem características não paramétricas.

Diante disso, o teste de Kruskal-Wallis foi adotado como método para testar as hipóteses da pesquisa. Segundo Maroco (2003), o teste de Kruskal-Wallis é uma alternativa não paramétrica ao teste ANOVA, podendo ser utilizado para testar se duas ou mais amostras provêm de uma mesma população ou se de populações diferentes, também, para examinar diferenças de médias para duas ou mais amostras.

\section{APRESENTAÇÃO E ANÁLISE DOS RESULTADOS}

Para a consecução do objetivo proposto, realizou-se, inicialmente, a análise descritiva dos dados, conforme apresentada na Tabela 6.

Tabela 6 - Análise descritiva dos dados

\begin{tabular}{lrr}
\hline Ano & Média & Desvio Padrão \\
\hline 2005 & $635.734,00$ & $3.383 .584,87$ \\
2006 & $1.067 .351,78$ & $5.399 .070,98$ \\
2007 & $1.104 .458,03$ & $6.599 .219,83$ \\
2008 & $1.828 .870,20$ & $8.996 .763,65$ \\
2009 & $1.292 .844,10$ & $7.417 .798,65$ \\
2010 & $1.991 .976,23$ & $7.866 .653,12$ \\
2011 & $2.068 .436,06$ & $9.503 .834,64$ \\
\hline
\end{tabular}

Fonte: os autores.

Verifica-se que os municípios brasileiros apresentaram um crescimento médio considerável com investimentos públicos até o ano de 2008. No período de 2009, a média de investimentos sofreu decréscimo de, aproximadamente, 30\%. Também, que os municípios apresentaram resultados, em relação à aplicação de recursos em investimentos, mais homogêneos nos primeiros anos da análise, em decorrência de menores valores dos desvios padrão. No Gráfico 1, evidencia-se o comportamento dos investimentos municipais no decorrer do período analisado. 
Gráfico 1 - Comportamento dos gastos médios com investimentos públicos municipais

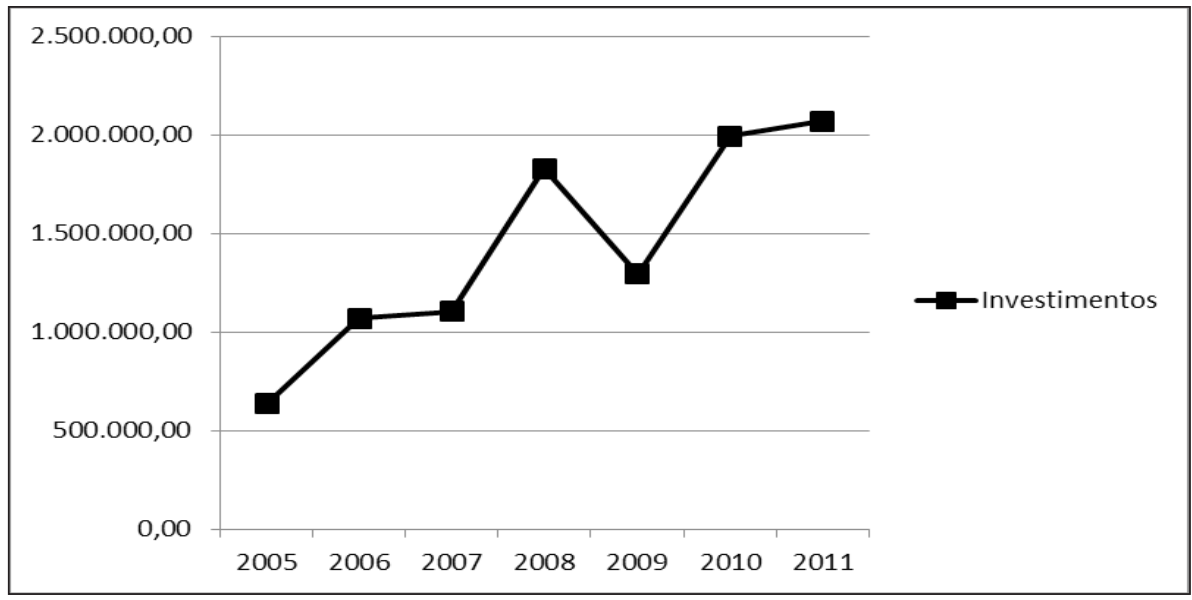

Fonte: os autores.

No Gráfico 1, observa-se que os investimentos municipais registraram crescimento até 2008, sofreram queda acentuada em 2009 e voltaram a crescer a partir de 2010. Nota-se que apesar da redução abrupta observada um ano após a crise, os valores dos investimentos no ano seguinte apresentaram-se superiores a 2008, indicando, preliminarmente, que os efeitos da crise impactaram os investimentos públicos municipais no ano seguinte ao da crise; porém, fica evidente que a reação à crise foi rápida e seus efeitos foram mitigados nos períodos seguintes.

Para se chegar a conclusões mais robustas, realizou-se o teste de Kruskal-Wallis para a amostra da pesquisa. A preparação dos dados para aplicação do teste pressupõe a divisão da amostra em duas subamostras, antes e após a crise financeira de 2008. O objetivo é determinar se as médias dessas subamostras são iguais; caso a significância do teste seja menor que 5\% (Sig.<0,05), rejeita-se a hipótese de que as médias são iguais e se assume que as médias dos dois grupos testados são diferentes. No caso dessa pesquisa, isso indicaria que os gastos com investimentos municipais “antes” e “após” a crise financeira de 2008 seriam diferentes.

O teste indicou (Tabela 7) que os municípios brasileiros, de modo geral, apresentaram uma diferença significativa entre as médias dos gastos com investimentos públicos antes e após a crise internacional, em razão de a Significância registrada ser de 0,000. 
Tabela 7 - Resultado do teste de Kruskal-Wallis

\begin{tabular}{llllll}
\hline \multicolumn{1}{l}{ Teste Kruskal-Wallis } & & & \\
\hline \multirow{4}{*}{ Investimentos } & Crise & Observações & Média & Test Statistics & Média Geral \\
& Antes & 10347 & 8792,78 & Chi-Square & 1401,593 \\
& Após & 10347 & 11902,22 & Df & 1 \\
\cline { 2 - 6 } & Total & 20694 & & Significância & 0,0000
\end{tabular}

Fonte: os autores.

Os resultados indicam que, de forma abrangente, os investimentos públicos aumentaram no período após a crise, sugerindo que os gestores públicos priorizaram a adoção de políticas públicas voltadas a minimizar os efeitos da crise financeira de 2008.

Para determinar em qual dos períodos, subsequentes à crise financeira internacional, os gastos com investimentos públicos apresentaram diferenças de médias em comparação com as do ano 2008, foram realizados três testes de Kruskal-Wallis, comparando os valores dos anos 2009, 2010 e 2011 com os de 2008; na Tabela 8 apresenta-se esse comparativo.

Tabela 8 - Resultado do teste de Kruskal-Wallis

\begin{tabular}{lrrrr}
\hline \multirow{2}{*}{ Período } & & Crise & \multirow{2}{*}{ Chi-Square } & Significância \\
\cline { 2 - 3 } & Antes & Após & & 0,000 \\
$2008-2009$ & 3751,59 & 3147,41 & 158,735 & 0,001 \\
$2008-2010$ & 3371,54 & 3527,46 & 10,572 & 0,000 \\
\hline
\end{tabular}

Fonte: os autores.

Com base nos valores das significâncias apresentadas (0,000), rejeita-se, nas três análises, a hipótese de que as médias dos gastos com investimentos públicos de 2009, 2010 e 2011, quando comparadas com a de 2008, são iguais, indicando a existência de diferenças de médias.

Verificou-se que do ano 2008 para 2009 houve uma redução significativa dos investimentos locais, indicando que os efeitos decorrentes da crise do sistema financeiro de 2008 refletiram no montante das despesas com investimentos realizados pelos municípios, mais fortemente em 2009, e que nos anos subsequentes esse efeito foi minimizado pelo crescimento dos montantes de gastos realizados pelos governos municipais em investimentos públicos.

Com base nos testes estatísticos realizados, rejeita-se a Hipótese 1, de que os níveis de investimentos locais não sofreram impactos da crise financeira internacional de 2008, para o ano 2009, em razão de a Significância registrada ser de 0,000 e de os valores médios serem menores que os de 2008. 
Na pesquisa propôs-se analisar, entre os diferentes portes populacionais dos municípios brasileiros, quais foram os estratos em que os gastos com investimentos públicos foram influenciados pelos efeitos da crise financeira de 2008.

Para testar a $\mathrm{H}_{2}$ da pesquisa, de que os municípios de menor porte foram os mais afetados pela crise financeira de 2008, foi realizado o teste de média em municípios de diferentes faixas populacionais, conforme a Tabela 9.

Tabela 9 - Resultado do teste de Kruskal-Wallis dos municípios brasileiros por faixa populacional

\begin{tabular}{|c|c|c|c|c|}
\hline \multirow{2}{*}{ Habitantes $(*)$} & \multicolumn{2}{|l|}{ Crise } & \multirow{2}{*}{ Chi-Square } & \multirow{2}{*}{ Significância } \\
\hline & Antes & Depois & & \\
\hline Abaixo 5.000 & 1968,28 & 3066,72 & 718,903 & 0,000 \\
\hline 5.001 a 20.000 & 3788,33 & 5548,67 & 995,648 & 0,000 \\
\hline 20.001 a 50.000 & 1748,88 & 2158,12 & 128,600 & 0,000 \\
\hline 50.001 a 100.000 & 591,84 & 597,16 & 0,071 & 0,789 \\
\hline 100.001 a 500.000 & 524,01 & 490,99 & 3,221 & 0,073 \\
\hline 500.000 a 1.000 .000 & 65,22 & 61,78 & 0,280 & 0,597 \\
\hline Acima de 1.000 .001 & 47,67 & 43,33 & 0,619 & 0,431 \\
\hline
\end{tabular}

Fonte: os autores.

Nota: (*) A estratificação seguiu a do Instituto Brasileiro de Geografia e Estatística (IBGE).

Os resultados evidenciaram que os municípios com população de até 50.000 habitantes apresentaram diferença significativa no volume de investimentos, sugerindo que a elevada dependência de recursos federais fez com que os municípios menores fossem mais impactados pela Crise Financeira 2008, não sendo possível rejeitar a $\mathrm{H}_{2}$ do estudo.

\section{CONCLUSÃO}

Em 2008, foi vivenciada uma nova crise mundial, causada por problemas bancários, decorrentes da oferta abundante de crédito destinado à compra de imóveis nos Estados Unidos, denominada bolha imobiliária americana, que resultou na falência de grandes bancos estadunidenses, tendo como principal consequência a escassez de crédito em nível global. Para contornar a crise, foram feitos rearranjos no setor financeiro, cortes de juros, e os governos de diversos países precisaram disponibilizar crédito aos agentes econômicos para evitarem retrações em suas economias e mitigarem os efeitos da crise instalada.

A crise financeira internacional abalou o desempenho da economia de vários países, aumentando o desemprego e reduzindo o volume do comércio mundial (MA- 
TIAS-PEREIRA, 2010). No Brasil, embora diversas medidas tenham sido tomadas para minimizar os efeitos da crise financeira, os municípios de menor porte sentiram o reflexo da turbulência econômica. Com o objetivo de analisar o impacto da crise financeira internacional de 2008 sobre os gastos com investimentos públicos dos municípios brasileiros no período de 2005 a 2011, na presente pesquisa se buscou constatar a existência de diferença entre as médias dos investimentos municipais “antes” e "após” a referida crise. Posteriormente à realização dos testes paramétricos, constatou-se que a amostra não apresentava característica normal; diante disso, adotou-se o teste não paramétrico de Kruskal-Wallis para testar as hipóteses da pesquisa.

Os gastos com investimentos públicos realizados pelos municípios brasileiros apresentam características diferentes das outras naturezas de despesa, como, por exemplo: a) são fortemente influenciados pelas transferências de recursos com destinação específica, por parte da União e dos Estados para os Municípios, como é o caso dos convênios; b) os impactos positivos da realização desses gastos com a população municipal, que, geralmente, estão associados à expansão e/ou melhoria dos serviços públicos municipais, especialmente, nos de menor porte; c) as questões políticas inerentes ao processo de escolha dos prefeitos municipais, no qual a figura do realizador de obras é vista como garantia de certas vantagens no pleito eleitoral.

Os resultados da pesquisa indicaram que o montante dos gastos com investimentos públicos municipais, que até o ano 2008 estava aumentando período após período, sofreu uma queda abrupta no ano subsequente ao da crise, 2009, voltando a normalizar-se nos anos 2010 e 2011, inclusive ultrapassando os montantes registrados antes da crise de 2008.

Os testes estatísticos revelaram que os impactos da crise financeira de 2008, no caso dos gastos com investimentos públicos municipais, ocorreram fortemente no ano 2009, ou seja, no período subsequente ao seu desencadeamento, possibilitando refutar a $\mathrm{H}_{1}$, de que os níveis de investimentos locais não foram influenciados pela crise de 2008. Evidenciaram, ainda, que os municípios brasileiros retornaram à tendência de aumentos sucessivos de seus níveis de gastos com investimentos públicos, conforme registrado nos anos anteriores a 2008.

Constatou-se, também, que municípios com população inferior a 50.000 habitantes foram os mais atingidos pelo impacto da crise financeira de 2008, confirmando a $\mathrm{H}_{2}$ da pesquisa, de que os níveis de investimentos públicos locais sofreram mais restrições nos municípios de menor porte populacional. Isso ocorreu, certamente, pela maior dependência financeira que esses estratos de municípios têm em relação às transferências constitucionais dos entes superiores (União e Estados). 
Essa retomada dos níveis de gastos em investimentos municipais pode ser decorrente de medidas preventivas adotadas pelo Brasil como forma de suavizar o efeito da crise financeira de 2008, fato esse que não foi objeto de análise nesta pesquisa. Porém, este estudo empírico abre espaço para investigações futuras que busquem explicar os fatores que contribuíram para, em um momento de crise sistêmica, os municípios brasileiros terem registrado incrementos em seus níveis de gastos com investimentos públicos.

\section{REFERÊNCIAS}

ALMEIDA, M. H. T. de; CARNEIRO, L. P. Liderança local, democracia e políticas públicas no Brasil. Opinião Pública, v. 9, n. 1, p. 124-147, 2003. Disponível em: <http://dx.doi.org/10.1590/S0104-62762003000100005>. Acesso em: 17 maio 2015.

ANDRADE, N. A. Contabilidade pública na gestão municipal. 3. ed. São Paulo: Atlas, 2007.

ARRETCHE, M.; VAZQUEZ, D. A. Distribuição espacial do gasto público no município de São Paulo: partidos fazem diferença? In: ENCONTRO ANUAL DA ANPOCS, 29., 2005, São Paulo. Anais... São Paulo, 2005. Disponível em: $<$ http://portal.anpocs.org/portal/index.php?option=com_docman\&task=doc_ view\&gid=3792\&Itemid=318>. Acesso em: 26 maio 2015.

BORGES, A. Federalismo, dinâmica eleitoral e políticas públicas no Brasil: uma tipologia e algumas hipóteses. Sociologias, Porto Alegre, v. 12, n. 24, p. 120-157, maio/ago. 2010. Disponível em: <http://www.scielo.br/scielo.php?pid=S151745222 010000200006\&script=sci_arttext>. Acesso em: 26 maio 2015.

BRESSER-PEREIRA, L. C. Crise e recuperação da confiança. Revista Economia e Política, v. 29, n. 1, 2009. Disponível em: <http://www.iececon.net/arquivos/publicacoes347527252.pdf>. Acesso em: 05 abr. 2015.

CARCANHOLO, M. et al. Crise Financeira Internacional: Natureza e Impacto. 2008. Disponível em: <http://www.ie.ufrj.br/hpp/intranet/pdfs/crise_financeira_internacional_gep_maio_2008.pdf>.Acesso em: 03 abr. 2015.

DALL’ACQUA, F. M. O Regime Fiscal e Investimento Público no Brasil. FGVEAESP/ GVPESQUISA, Relatório 21/2005. Disponível em: <http://virtualbib.fgv.br/dspace/bitstream/handle/10438/3156/P00333_1.pdf?sequence=1>. Acesso em: 10 maio 2015. 
DOMINGUES, E. P.; VIANA, F. D. F.; OLIVEIRA, H. C. de. Investimentos em infra-estrutura no Nordeste: projeções de impacto e perspectivas de desenvolvimento. Belo Horizonte: FMG/Cedeplar, 2007. Disponível em: <http://www.cedeplar. ufmg.br/pesquisas/td/TD\%20319 .pdf>. Acesso em: 16 fev. 2015.

GONÇALVES, R. Crise Econômica: Radiografia e Soluções para o Brasil. 2008. Disponível em: <http://www.socialismo.org.br/portal/images arquivo/criserenato. pdf>. Acesso em: 02 maio 2015.

KOHAMA, H. Contabilidade pública: teoria e prática. 11. ed. São Paulo: Atlas, 2010.

MAROCO, J. Análise estatística com utilização do SPSS. 2. ed. Lisboa: Síbalo, 2003.

MATIAS-PEREIRA, J. Finanças Públicas: a política orçamentária no Brasil. 5. ed. São Paulo: Atlas, 2010.

NASCIMENTO, E. R. Gestão Pública: tributação e orçamento; gestão fiscal responsável; lei de responsabilidade fiscal; tópicos em contabilidade pública; gestão pública no Brasil, de JK a Lula; administração financeira e orçamentária; finanças públicas nos três níveis de governo. São Paulo: Saraiva, 2006.

RIBEIRO, F. et al. Capital de Giro: uma análise de Empresas do Setor de Papel e Celulose listadas na BM\&FBovespa. In: CONGRESSO INTERNACIONAL DE ADMINISTRAÇÃO, 2011, Ponta Grossa. Anais... Ponta Grossa: ADM, 2011.

SLOMSKI, V. Manual de contabilidade pública: um enfoque na contabilidade municipal, de acordo com a Lei de Responsabilidade Fiscal. 2. ed. São Paulo: Atlas, 2006.

SOUZA, C. Federalismo, desenho constitucional e instituições federativas no Brasil pós-1988. Revista Sociologia Política, n. 24, p. 105-121, jun. 2005. Disponível em: <http://www.scielo.br/pdf/rsocp/n24/a08n24.pdf>. Acesso em: 16 maio 2015.

SOUZA, C. Governos e sociedades locais em contextos de desigualdades e de descentralização. Ciência \& Saúde Coletiva, v. 7, n. 3, p. 431-442, 2002. Disponível em: <http://www.scielo.br/pdf/csc/v7n3/13023>. Acesso em: 20 ago. 2015. 
SOUZA, C. Governos locais e gestão de políticas sociais universais. São Paulo em Perspectiva, v. 18, n. 2, p. 27-41, 2004. Disponível em: <http://www.scielo.br/pdf/ spp/v18n2/a04v18n2.pdf>. Acesso: 26 maio 2015.

TESOURO NACIONAL. Finanças do Brasil - FINBRA - 2005 a 2011. Disponível em: <http://www3.tesouro.gov.br/estados_municipios/index.asp>. Acesso em: 10 mar. 2015.

UNITED STATES OF AMERICA. The financial crisis inquiry report: final report of the National Commission on the causes of the financial and economic crisis in the United States. Washington: Official Government Edition, 2011.

Com citar este artigo:

\section{ABNT}

RIBEIRO, Flávio; GERIGK, Willson. O impacto da crise financeira internacional sobre os investimentos públicos municipais. RACE: Revista de Administração, Contabilidade e Economia, Joaçaba: Ed. Unoesc, v. 15, n. 1, p. 95-114, jan./abr. 2016. Disponível em: <http://editora.unoesc.edu.br/index.php/race>. Acesso em: dia/mês/ ano.

\section{APA}

Ribeiro, F., \& Gerigk, W. (2016). O impacto da crise financeira internacional sobre os investimentos públicos municipais. Efeitos do uso da informação "Edição limitada sobre percepções de preço e intenção de compra de produtos. RACE: Revista de Administração, Contabilidade e Economia, 15(1), 95-114. Recuperado em dia/mês/ ano, de http://editora.unoesc.edu.br/index.php/race 